\title{
A genetic linkage map of Pleurotus tuoliensis integrated with physical mapping of the de novo sequenced genome and the mating type loci
}

Wei Gao ${ }^{1,2}$, Jibin Qu ${ }^{1,2}$, Jinxia Zhang ${ }^{1,2}$, Anton Sonnenberg ${ }^{3}$, Qiang Chen ${ }^{1,2}$, Yan Zhang ${ }^{1,2}$ and Chenyang Huang ${ }^{1,2^{*}}$ (D)

\begin{abstract}
Background: Pleurotus tuoliensis (Bailinggu) is a commercially cultivated mushroom species with an increasing popularity in China and other Asian countries. Commercial profits are now low, mainly due to a low yield, long cultivation period and sensitivity to diseases. Breeding efforts are thus required to improve agronomical important traits. Developing saturated genetic linkage and physical maps is a start for applying genetic and molecular approaches to accelerate the precise breeding programs.

Results: Here we present a genetic linkage map for $P$. tuoliensis constructed by using 115 haploid monokaryons derived from a hybrid strain $\mathrm{H} 6$. One thousand one hundred and eighty-two SNP markers developed by 2b-RAD (type IIB restriction-site associated DNA) approach were mapped to 12 linkage groups. The map covers $1073 \mathrm{cM}$ with an average marker spacing of $1.0 \mathrm{cM}$. The genome of $P$. tuoliensis was de novo sequenced as $40.8 \mathrm{Mb}$ and consisted of 500 scaffolds (>500 bp), which showed a high level of colinearity to the genome of $P$. eryngii var. eryngii. A total of $97.4 \%$ SNP markers (1151) were physically localized on 78 scaffolds, and the physical length of these anchored scaffolds were $33.9 \mathrm{Mb}$ representing $83.1 \%$ of the whole genome. Mating type loci A and B were mapped on separate linkage groups and identified physically on the assembled genomes. Five putative pheromone receptors and two putative pheromone precursors were identified for the mating type B locus.

Conclusions: This study reported a first genetic linkage map integrated with physical mapping of the de novo sequenced genome and the mating type loci of an important cultivated mushroom in China, P. tuoliensis. The de novo sequenced and annotated genome, assembled using a 2b-RAD generated linkage map, provides a basis for marker-assisted breeding of this economic important mushroom species.
\end{abstract}

Keywords: Linkage mapping, Physical mapping, 2b-RAD approach, Genotyping by sequencing, Single nucleotide polymorphism, Mating type loci

\footnotetext{
* Correspondence: huangchenyang@caas.cn

${ }^{1}$ Institute of Agricultural Resources and Regional Planning, Chinese Academy of Agricultural Sciences, Beijing, China

${ }^{2}$ Key Laboratory of Microbial Resources, Ministry of Agriculture, Beijing, China

Full list of author information is available at the end of the article
} 


\section{Background}

Pleurotus tuoliensis is a white-colored commercially cultivated mushroom species. Bailinggu is the trade name used in China. Wild Bailinggu usually grows in association with roots of Ferula plants. Several scientific names have been used for this species, i.e. P. nebrodensis [1], P. ferulae and P. eryngii var. tuoliensis [2]. A recent taxonomic study defined $P$. tuoliensis as an independent species rather than a variety or subspecies of $P$. eryngii [3], although the two species are close related $[4,5] . P$. tuoliensis has been cultivated in China commercially for more than 15 years. There is a recent interest in this species also in other countries like Korea and Japan, where this species is now imported or even cultivated.

Bailinggu is one of the highest priced mushrooms on the market due to its pure white color, particular flavor and also its health-protecting function [6]. However, the profits of Bailinggu cultivation are relatively low, compared to the king oyster mushrooms, $P$. eryngii var. eryngii. The high price and the low profits are results of the high production cost, mainly due to the long production period, the low yield and the sensitivity to diseases. There is thus a need for new cultivars with a reduced production time, better yield and resistance to diseases. There is a large collection of $P$. tuoliensis germplasm built in CCMSSC (China Center for Mushroom Spawn Standards and Control) [3]. Wild strains carrying superior traits of interest were detected in previous screening programs. Nevertheless, hardly any new cultivars were released on market in the past few years. Most of the economic and agronomic characters are likely quantitative traits under polygenic control making conventional breeding such as phenotypic selection a laborious task. Marker-assisted breeding has not been applied to this mushroom species yet. The identification of genetic markers linked to these complex traits will facilitate the marker-assisted selection and accelerate the breeding progress.

High-resolution genetic linkage maps are prerequisites for quantitative genetic studies and mapping candidate genes in quantitative trait loci (QTL). These maps are also valuable tools for the detection of recombination hotspots, the comparative genomic analysis and chromosome-scale scaffolding. Genetic linkage maps were generated for a number of mushroom species, including Agaricus bisporus [7-9], P. ostreatus [10, 11], Lentinula edodes [12, 13], P. eryngii $[14,15]$, and $A$. subrufescens [16]. For all of these species a more or less complete genome sequence is available. So far, there is no report for genetic linkage mapping and the whole genome sequence for $P$. tuoliensis. Since $P$. eryngii var. eryngii and $P$. tuoliensis are closely related species, the latest map of $P$. eryngii var. eryngii consisted of 12 linkage groups spanning $1047.8 \mathrm{cM}$ might be a reference for mapping in P. tuoliensis [14].

The availability of a large number of markers are crucial for constructing a high-density map. Single-nucleotide polymorphisms (SNPs) have become the markers of choice in genetic studies with the development of the next generation sequencing techniques. Genotyping-by-sequencing (GBS) is a high-throughput method for simultaneously discovering and genotyping thousands of SNP markers. Recently, restriction-site associated DNA (RAD) has been designed as an adaptation to GBS [17]. This so called $2 \mathrm{~b}-$ RAD, uses Type IIB restriction enzymes to generate a RAD library [18]. It has been used for the construction of highresolution linkage maps [19-21], and appeared to be rapid and cost effective compared to other SNP detection and genotyping methods.

Next to marker-assisted selection, knowledge on the mating system is of crucial importance for breeding [22]. Mating incompatibility is often a limitation for introgression breeding of mushroom species. P. tuoliensis has a heterothallic life cycle with a tetrapolar mating system [5]. The mating of tetrapolar system is determined by two unlinked mating type loci, i.e. A and B. Only monokaryons differing in both mating type loci are compatible to form dikaryons and initiate sexual life cycle. The A locus regulates nuclear pairing, formation of the clamp connections, and nuclear division; the B locus promotes septal dissolution, nuclear migration towards the apical cells and fusion of clamp connection cells. The activation of both $\mathrm{A}$ and $\mathrm{B}$ determines the compatibility and the possibility of producing fruiting bodies [23, 24]. The mating system of several mushroom species have been reported in terms of genetic structure and functions, e.g. A. bisporus [25], L. edodes [24, 26], P. djamor [27], P. eryngii [28, 29] and Volvariella volvacea [30], etc. In a tetrapolar mating system, genes in locus A encode homeodomain (HD) transcription factors, and that of locus $\mathrm{B}$ encodes pheromone receptor and pheromone precursor genes [23]. The A loci of basidiomycetes are characterized by two classes of homeodomain transcription factors HD1 and HD2. They are usually located side by side with opposite orientations. Most basidiomycete have one pair, and some two or even three pair of HD genes [31]. The flanking region of the A mating locus in basidiomycete is also conserved and can be used to clone the less conserved HD genes. The mating type locus A (matA) and the flanking genes of P. tuoliensis were partially available on GenBank (HQ595187.1; HQ595186.1; HQ595185.1). Nevertheless, the structure and the gene order of matA remains unknown, and no information was available for the locus B of P. tuoliensis. Typically, mating type locus B (matB) contains at least a pheromone precursor and a pheromone receptor [32]. However, mushrooms of different species vary in the structure of matB. Four pheromone and four receptor genes were identified in $P$. eryngii with a physical length of less than $12 \mathrm{~Kb}$ [28]; the matB of $L$. edodes also contains four pheromone and four receptors [26]; Coprinopsis 
cinerea has three sub-groups with multiple pheromones and one receptor in each sub-group [33]; Schizophyllum commune possesses two functionally independent sub-loci containing one receptor and several pheromones [34].

We reported here a saturated genetic linkage map with an integrated physical map of $P$. tuoliensis. The genetic linkage map was constructed based on a population of 115 monokaryons derived from a hybrid strain. SNP markers were developed and genotyped by using $2 \mathrm{~b}-$ RAD approach. The rates and distribution of meiotic recombination along the genome were investigated. Physical mapping of scaffolds from the de novo sequenced genome is presented using the mapped SNP markers as anchors. Furthermore, we presented the mapping and identification of the mating type loci.

\section{Results}

\section{Genotyping by $2 \mathrm{~b}-\mathrm{RAD}$ approach}

BsaXI libraries were constructed for the two parental lines and the progeny. Sequencing of the libraries produced 0.6-1.6 million high-quality reads per individual with an average of 1.1 million. The average sequencing depth was 49 fold. A total of 1770 SNP markers were identified. Doubtful markers showed errors and/or more than $20 \%$ missing values, which were omitted in subsequent analyses. All individuals of the segregating population were confirmed to be monokaryons with the genotyping data.

\section{High-density genetic map construction}

Totally, 1711 SNP markers were used for the linkage analysis, of which 283 markers (16.5\%) deviate from the expected 1:1 ratio $(P \leq 0.05)$ and were excluded in the linkage analysis. At the LOD (logarithm of odds) threshold of 6.0, 1182 markers (including the two mating type loci) were assigned to 12 linkage groups (LGs) (Fig. 1). The map covers a total length of $1073 \mathrm{cM}$, with an average distance between adjacent markers of $1.0 \mathrm{cM}$. The size of linkage groups ranges from $24.7 \mathrm{cM}$ to $166.8 \mathrm{cM}$ (Table 1). The number of markers per group ranges

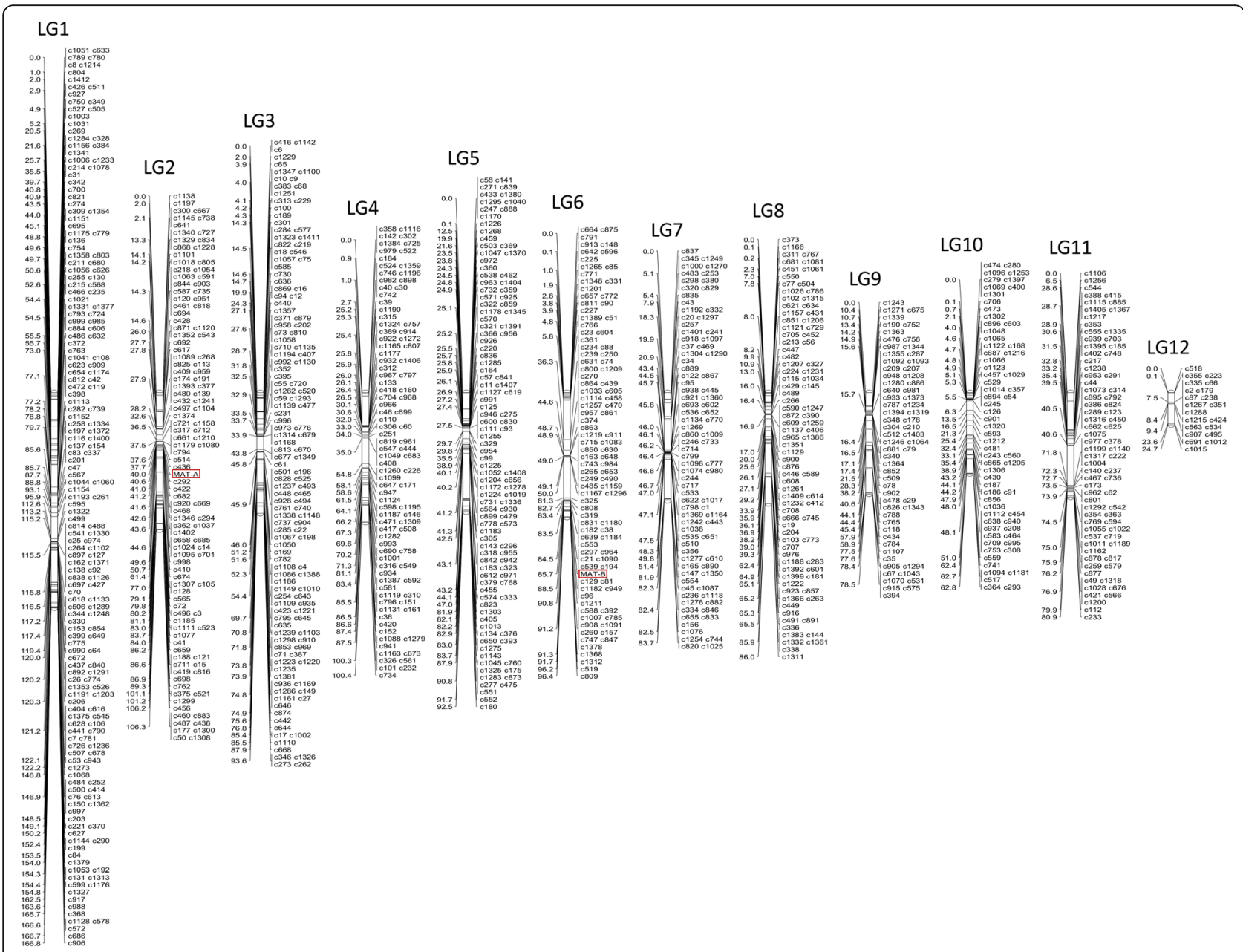

Fig. 1 Genetic linkage map of $P$. tuoliensis. Marker positions (cM) and names are presented on the left and right side of each linkage group (LG), respectively. Markers labeled with frames are the two mating type loci 
Table 1 Characteristics of the genetic linkage map of $P$. tuoliensis

\begin{tabular}{|c|c|c|c|c|c|c|c|c|c|c|c|c|c|c|c|}
\hline \multirow[t]{2}{*}{$\begin{array}{l}\text { Linkage } \\
\text { group }\end{array}$} & \multirow[t]{2}{*}{$\begin{array}{l}\text { Mapped } \\
\text { physical } \\
\text { length (Mbp) }\end{array}$} & \multirow[t]{2}{*}{$\begin{array}{l}\text { No. of } \\
\text { Scaffold }\end{array}$} & \multirow[t]{2}{*}{$\begin{array}{l}\text { Map } \\
\text { length } \\
\text { (cM) }\end{array}$} & \multirow[t]{2}{*}{$\begin{array}{l}\text { Size ratio } \\
\text { (Kbp/cM) }\end{array}$} & \multirow[t]{2}{*}{$\begin{array}{l}\text { No. of } \\
\text { markers }\end{array}$} & \multirow[t]{2}{*}{$\begin{array}{l}\text { No. of co- } \\
\text { segregating } \\
\text { markers }\end{array}$} & \multirow[t]{2}{*}{$\begin{array}{l}\text { Average marker } \\
\text { spacing (CM) }\end{array}$} & \multirow[t]{2}{*}{$\begin{array}{l}\text { Largest } \\
\text { interval } \\
\text { (cM) }\end{array}$} & \multicolumn{6}{|c|}{$\begin{array}{l}\text { No. of } \\
\text { crossovers }\end{array}$} & \multirow[t]{2}{*}{$\begin{array}{l}\text { Mean } \\
\text { crossover } \\
\text { frequency }\end{array}$} \\
\hline & & & & & & & & & 0 all $a^{1}$ & 0 all b ${ }^{2}$ & 1 & 2 & 3 & 4 & \\
\hline LG1 & 4.97 & 8 & 166.79 & 29.80 & 197 & 113 & 0.8 & 24.6 & 9 & 8 & 55 & 31 & 9 & 3 & 1.36 \\
\hline LG2 & 4.43 & 7 & 106.26 & 41.69 & 118 & 62 & 0.9 & 15.9 & 21 & 13 & 46 & 19 & 7 & 9 & 1.23 \\
\hline LG3 & 4.29 & 8 & 93.63 & 45.82 & 140 & 87 & 0.7 & 15.3 & 16 & 25 & 57 & 16 & 1 & 0 & 0.80 \\
\hline LG4 & 3.02 & 10 & 100.41 & 30.08 & 97 & 51 & 1.0 & 22.5 & 19 & 24 & 51 & 17 & 4 & 0 & 0.84 \\
\hline LG5 & 3.09 & 8 & 92.46 & 33.42 & 115 & 53 & 0.8 & 34.9 & 26 & 19 & 50 & 5 & 9 & 6 & 0.97 \\
\hline LG6 & 2.39 & 9 & 96.40 & 24.79 & 101 & 60 & 1.0 & 31.5 & 19 & 25 & 54 & 12 & 0 & 5 & 0.85 \\
\hline LG7 & 3.34 & 4 & 83.74 & 39.88 & 91 & 50 & 0.9 & 30.5 & 22 & 30 & 46 & 10 & 4 & 3 & 0.78 \\
\hline LG8 & 2.15 & 7 & 86.02 & 24.99 & 92 & 50 & 0.9 & 23.1 & 17 & 28 & 60 & 7 & 3 & 0 & 0.72 \\
\hline LG9 & 2.02 & 6 & 78.52 & 25.72 & 65 & 29 & 1.2 & 18.6 & 30 & 14 & 57 & 4 & 8 & 2 & 0.84 \\
\hline LG10 & 1.78 & 9 & 62.81 & 28.34 & 66 & 28 & 1.0 & 14.4 & 27 & 30 & 51 & 0 & 7 & 0 & 0.63 \\
\hline LG11 & 1.52 & 4 & 80.88 & 18.79 & 79 & 44 & 1.0 & 31.2 & 28 & 23 & 50 & 5 & 6 & 3 & 0.78 \\
\hline LG12 & 0.89 & 3 & 24.67 & 36.08 & 21 & 13 & 1.2 & 14.2 & 54 & 39 & 20 & 2 & 0 & 0 & 0.21 \\
\hline Total & 33.9 & 78 & 1072.6 & & 1182 & 640 & 11.4 & 276.7 & 234 & 239 & 577 & 126 & 58 & 31 & 10.01 \\
\hline Average & 2.8 & 6.5 & 89.4 & 31.6 & 98.5 & 53.3 & 1.0 & 23.1 & 19.5 & 20 & 48 & 11 & 5 & 3 & 0.83 \\
\hline
\end{tabular}

${ }^{1}$ Number of individuals inherited the intact linkage group from H6PA

${ }^{2} \mathrm{Number}$ of individuals inherited the intact linkage group from $\mathrm{H} 6 \mathrm{~PB}$

from 21 on the smallest LG to 197 on the largest LG. Co-segregating markers represent $54 \%$ of all the markers. The largest marker interval per group ranges from $16.2 \mathrm{cM}$ to $41.4 \mathrm{cM}$. The size ratio of genetic linkage map and genome is $31 \mathrm{Kbp} / \mathrm{cM}$.

Most of the monokaryotic offspring inherited half of the genetic information from each parental lines. Among all the individuals, the minimal proportions of parental genotypes were $26 \%$ and $18 \%$ inherited from H6PA and H6PB, respectively. The number of crossovers per individual ranged from 3 to 17 with an average of 10 . The frequency distribution of crossovers in the progeny showed an almost normal distribution (Additional file 1). For each LG, many individuals inherited the complete parental type (Table 1). The crossover frequency per linkage group per individual varied from 0.21 for LG12 to 1.36 for LG1, and the average was 0.83 .

\section{Genome sequencing, assembly and annotation}

The genome was assembled to be $40.83 \mathrm{Mb}$ consisted of 500 scaffolds ( $\geq 500$ bp) (Fig. 2). The longest scaffold is $3.39 \mathrm{Mb}$ (N50, $0.63 \mathrm{Mb}$; N90, $0.12 \mathrm{Mb}$ ). The size of total estimated gaps is $2.13 \mathrm{Mb}$ ( $5 \%$ of the whole genome). The $\mathrm{G}+\mathrm{C}$ content of the assembly is $50.22 \%$. A total of $66 \%$ of the clean short-insert reads were mapped to the draft sequence with about 230-fold coverage. Fourteen thousand two hundred and sixty-three gene models were predicted and confirmed by aligning to NR database, of which $92.7 \%$ (13224) have matches using the e-value threshold $1^{\mathrm{e}-5}$. The average length of the predicted gene models is 436 aa (Table 2). The total length of the coding sequences was $19.48 \mathrm{Mb}$ with a gene/genome ratio of $47.7 \%$. A total of $1.41 \mathrm{Mb}$ dispersed repetitive sequences (Table 3) and $0.29 \mathrm{Mb}$ tandem repeat (TR) sequences were identified representing $3.43 \%$ and $0.71 \%$ of the genome, respectively. The interspersed repeats (Additional file 2) are consisted of LTR (long terminal repeats), DNA transposons, LINEs (long interspersed nuclear elements), SINEs (short interspersed nuclear elements) and RC (rolling circle). The length of LTR accounts for 3\% of the Bailinggu genome. The predicted non-coding RNA is mainly consisted of 199 tRNA and 16 snRNA (small nucleolar RNAs) with a total length of $18.7 \mathrm{~Kb}$. The genome sequence of $P$. tuoliensis 489P1 has been deposited at the GenBank database under the accession number MKZX00000000. The whole genome sequences of $P$. tuoliensis and $P$. eryngii var. eryngii showed a high level of sequence colinearity (Fig. 3a). Linkage group 1 (LG1) represents the longest LG of the genetic linkage map of both $P$. tuoliensis and $P$. eryngii var. eryngii [14]. According to the physical positions of markers, the two LG1s anchored exactly the homologous chromosomes of $P$. tuoliensis and $P$. eryngii var. eryngii, respectively (Additional files 3 \& 4). A separate MUMmer plot of LG1 of both species shows its colinearity (Fig. 3b) with one putative translocation but only few inversions.

\section{Physical mapping of scaffolds in the genetic map}

To assign scaffolds to chromosomes, the mapped SNP markers were used as anchors. A total of 78 unique 


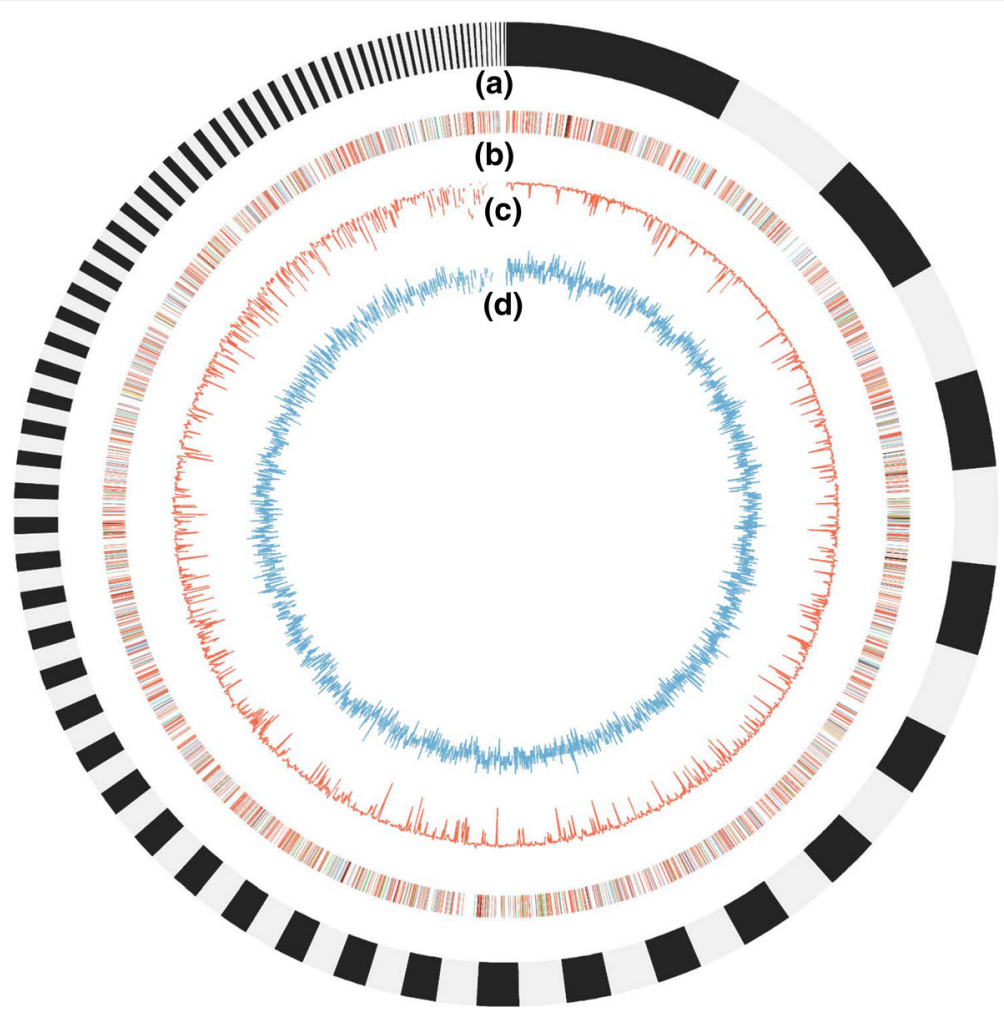

Fig. 2 Graphical representation of the genomic features of $P$. tuoliensis. a Scaffolds longer than $10 \mathrm{kbp}$ (145 scaffolds shown); b Distribution of transposable elements (TEs). Lines in color indicates the position of TES, of which LTR in red, DNA in blue, LINE in Green, SINE in yellow, and RC in brown; c GC content: the percentage of G + C in 10 kbp non-overlapping windows; d Gene density: the number of genes in 10 kbp nonoverlapping windows

scaffolds (containing two or more SNP markers) were anchored on the genetic map, representing $83.1 \%$ (33.9 Mb) of the current Bailinggu genome (Fig. 4). The markers were distributed homogenously on 78 scaffolds, and about $50.9 \%$ of the mapped SNPs (602) were located within the coding regions (Additional file 3). The LG with the highest number of scaffolds was LG2 consisted of 13 scaffolds anchoring a total of $4.4 \mathrm{Mb}$ physical length (Table 1). LG3 and LG4 had the lowest number of scaffolds (4 of each), which mapped 3.7 $\mathrm{Mb}$ and 2.9 $\mathrm{Mb}$ genome sequence, respectively. Scaffold 1 included the highest number of markers with 132 SNPs on LG 1, while scaffolds 53, 59, 100 , and 108 were tagged by only two markers each. Most scaffolds were mapped to single linkage groups apart from

Table 2 General features of the P. tuoliensis (CCMSSC00489) genome

\begin{tabular}{ll}
\hline Number of scaffolds (>500 bp) & 500 \\
Length of large scaffolds combined (Mb) & 40.83 \\
Size of the total estimated gaps (Mb) & 2.13 \\
GC content (\%) & 50.22 \\
Number of predicted gene models & 14,263 \\
Average length of the predicted gene models (aa) & 436 \\
\hline
\end{tabular}

scaffold 4, 8, 16 and 22. Scaffold 4 was divided by LG5 and LG10; scaffold 8 was divided by three different linkage groups (LG4, LG8 and LG10); scaffold 16 was by LG5 and LG10; scaffold 22 was by LG4 and LG6. This may suggest misassemblies of these scaffolds. The physical map comprises $33.9 \mathrm{Mb}$ genome corresponding to a total genetic distance of $1073 \mathrm{cM}$ giving a mean value of $31.6 \mathrm{Kbp} / \mathrm{cM}$. The ratio was different among linkage groups, from 18.8 $\mathrm{Kbp} / \mathrm{cM}$ for LG11 to $45.82 \mathrm{Kbp} / \mathrm{cM}$ for LG3. For each LG the map length was not correlated to the physical size.

\section{Mapping of the mating type genes}

Using the partial sequence of the matA locus of CCMSSC00489 (GenBank HQ595187.1), the mating type factor A (matA) of strain 489P1 was found to be located on scaffold 6 . The genotype of the mapping population for this region confirmed the identification of the mating types previously done by mating to the parental lines. The matA of $P$. tuoliensis was mapped to LG2 on the map position of $40 \mathrm{cM}$, and the flanking markers were physically located on scaffold 6 . The mating type factor B (matB) was mapped to LG6 on the map position of $85.7 \mathrm{cM}$, and the flanking markers were physically located on scaffold 21 and 22 . 
Table 3 Summary of the predicted interspersed repeats

\begin{tabular}{lllll}
\hline Type & Number & Total Length (bp) & In Genome (\%) & Average length (bp) \\
\hline LTR & 2772 & $1,233,493$ & 3.0020 & 451 \\
DNA transposon & 609 & 84,259 & 0.2051 & 141 \\
LINE & 462 & 63,180 & 0.1538 & 143 \\
SINE & 14 & 970 & 0.0024 & 69 \\
RC & 82 & 29,671 & 0.0722 & 369 \\
Unknown & 9 & 699 & 0.0017 & 78 \\
Total & 3948 & $1,407,823$ & 3.4263 & 364 \\
\hline
\end{tabular}

Comparison of the matA locus and flanking regions of $P$. eryngii var. eryngii and $P$. tuoliensis showed colinearity but also differences. $P$. tuoliensis contains two flanking HD genes with the same orientation as in $P$. eryngii. The latter has, however, an additional HD2 gene at the right site before the mip gene. The mip is tightly linked to matA in most basidiomycetes [27]. In P. tuoliensis, however, the HD genes seems to be separated by a cluster of genes (ca. $29 \mathrm{~Kb})$ from the mip gene according to the assemble genome sequence (Additional files 5 \& 6). In order to check if this is an artefact caused by misassembly, we designed primers in the flanking region (HD1 and mip gene). The amplification showed that the gene cluster is an artefact (Additional file 7). The matA locus of $P$. eryngii and $P$. tuoliensis are thus highly colinear.

The linkage mapping of the mating types indicated that matB is linked to scaffolds 21 and 22 . On both of which, a putative pheromone was identified via homologous blast. Two additional pheromone-like peptides were identified on scaffolds 47 and 85 . The multiple alignment indicated the homology of pheromones identified in different mushroom species (Additional file 8). A total of five genes presented strong homology to fungal pheromone receptors, of which four on scaffold 21 and one on scaffold 22 (Table 4). All the five have the signature of STE3 G protein-coupled receptors (GPCR) confirmed by Pfam search. As a result, the matB region consisted of a $44 \mathrm{~kb}$ genome fragment on scaffold 21 and a fragment of unknown length on scaffold 22 (Fig. 5). Since only two SNPs on scaffold 22 were mapped on LG6, length of the fragment enclosing the matB locus of this scaffold is uncertain. The identified genes of matB locus had strong homology to fungal pheromone receptors and pheromone precursors (Table 4). Phylogenetic analysis showed that the five pheromone receptors of $P$. tuoliensis were grouped into two clades, and two of them (P1A3188 and P1A3343) showed high similarity to that of P. eryngii var. eryngii (Fig. 6).

\section{Discussion}

The constructed genetic linkage map generated 12 LGs with a total genetic length of $1073 \mathrm{cM}$. Compared to the conventional GBS method, 2b-RAD approach appeared to be a more cost-effective method to generate markers since the use of selective adaptors generated a marker density of a desired level. Sequencing cost is further reduced by sequencing a subset of BsaXI sites derived from RTR (reduced tag representation) libraries [20]. The average sequencing depth $(49 \times)$ was sufficient for high-quality genotyping. This is a first report about $2 \mathrm{~b}-\mathrm{RAD}$ method used for discovering and genotyping SNPs for a mushroom species.

Distorted segregation of markers is commonly observed in linkage analysis. The percentage of skewed loci in this study $(16.5 \%)$ is higher than those found in mapping studies of other fungi, e.g. $3.8 \%$ in L. edodes [12], $8.95 \%$ in A. bisporus [8], $12.7 \%$ in P. eryngii [14], and $14 \%$ in P. ostreatus [10]. Germination rate of fungal spores can be influenced by the density of spore suspension that is plated since germinating spores induce the germination of additional spores [35]. Each spore might also react differently on the germination stimulation. Differences were observed in the time of spore germination after plating and the growth rate of mycelium in our study. In order to have an unbiased selection of germinated spores we, therefore, isolated SSIs from each dilution during one month with a large range of growth rate. Thus, it might be possible that some allele combinations are sub-lethal or lead to very slow germination and growth, which explains skewed segregation to some extent. All markers on scaffold 13, 32, 34, 35, 40, 46, 49, $56,63,64,70,79,94,116,269$ showed biased segregation, and $76 \%$ of the skewed markers are biased to the direction of parental line 489P1. These alleles might thus represent genomic areas of the parental line 489P1 that give a better germination or growth rate. This directional distortion was also detected in the study of $\mathrm{A}$. bisporus, but the reason for it was not clear [8]. Next to it, the activity of transposon elements (TEs) might also result in the biased segregated progeny by triggering gene silencing during meiotic reproduction [36, 37]. Nevertheless, TEs are probably not the main reason causing skewed segregation since they have been used as markers to conduct genetic linkage and genome-wide association mapping [38, 39]. 


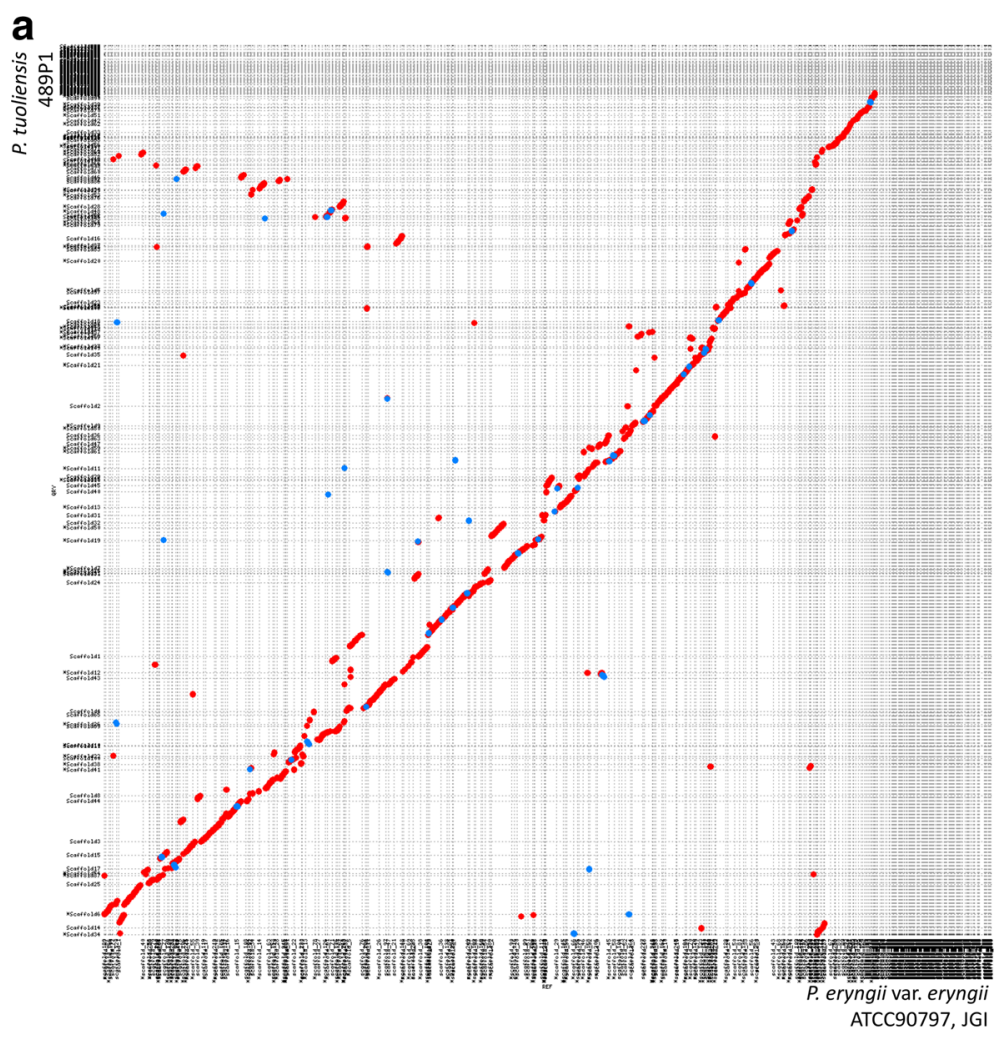

b

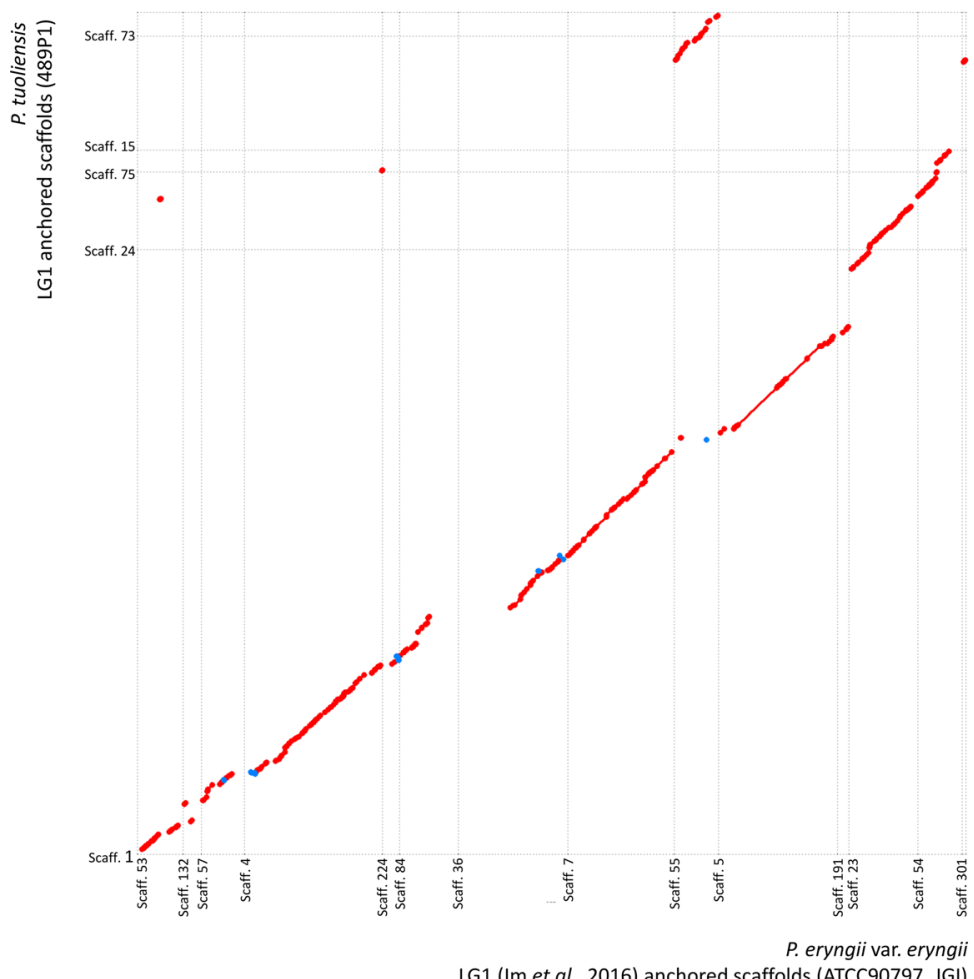

Fig. 3 (See legend on next page.) 
(See figure on previous page.)

Fig. 3 Colinear comparison of the genomes of $P$. tuoliensis and P. eryngii var. eryngii (JGI) using MUMmer plots. Plot a represents the comparison of the whole genomes; Plot $\mathbf{b}$ represents that of the homologous chromosomes anchored by LG1. The physical positions of markers anchored on scaffolds were available in Additional files 2 and 3. The red dots represent sequence collinear, and blue dots represent sequence inversion. Scattered dots represent repetitive sequences aligned on different genomic positions

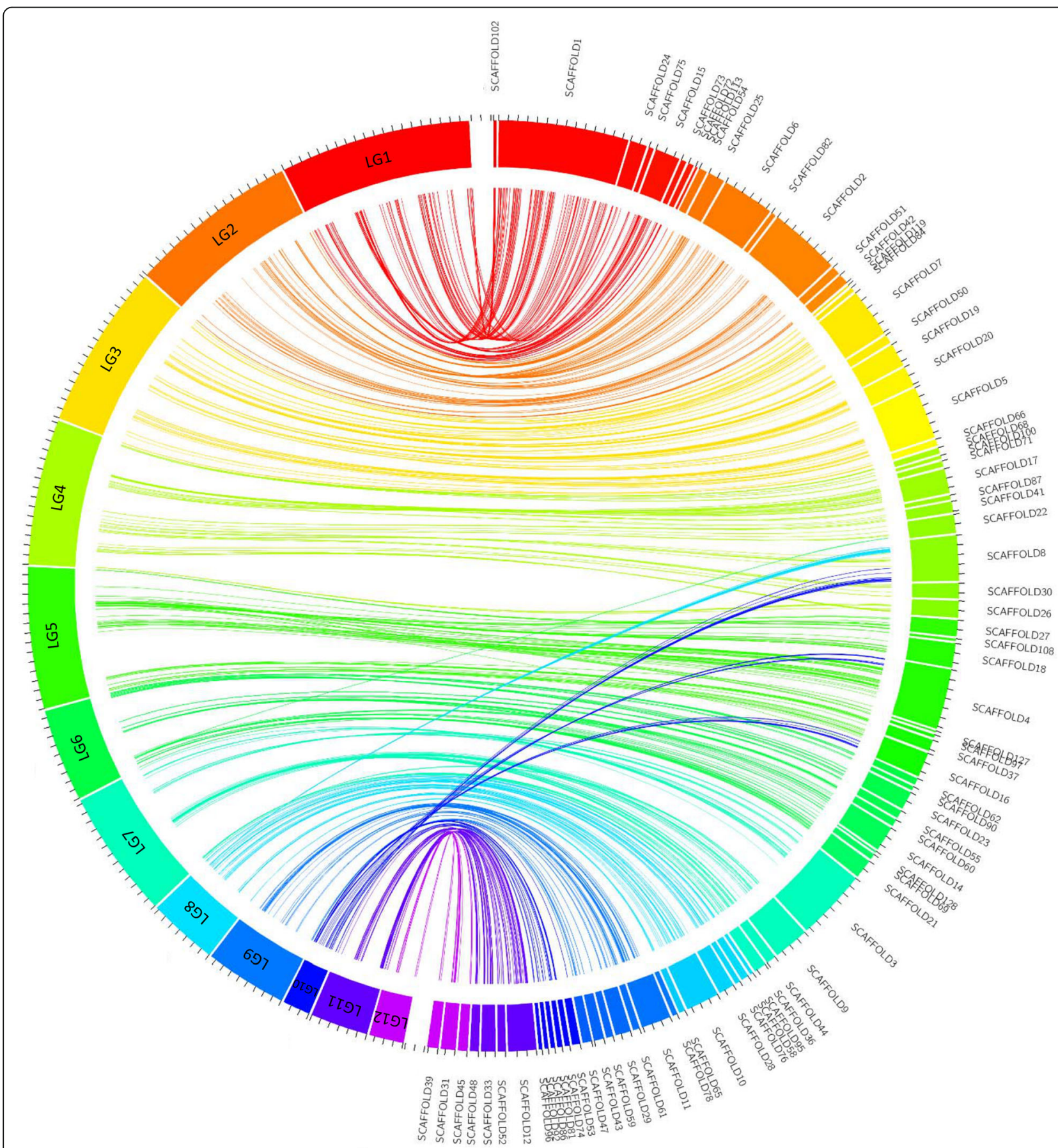

Fig. 4 Graphical representation of syntenic relationship between the genetic linkage map and the physical map of $P$. tuoliensis. Linkgage groups $(L G)$ are depicted in colors at the left side of the circle, and the physical map, i.e., the corresponding scaffolds are at the right side of the circle. Lines of the same colors connect the markers on LGs and physical positions on scaffolds. The diagram was plotted using Circos 0.69 [51] 
Table 4 Homologue genes identified in the B mating type locus and the flanking region of $P$. tuoliensis strain 489P1

\begin{tabular}{|c|c|c|c|c|c|c|c|c|}
\hline Gene & Position $^{a}$ & Species & $\begin{array}{l}\text { Homologue } \\
\text { gene }^{b}\end{array}$ & $\begin{array}{l}\text { GenBank } \\
\text { accession no. }\end{array}$ & E value & Bit score & Identity & $\begin{array}{l}\text { Conserved domain/ } \\
\text { motifs of encoded } \\
\text { protein }{ }^{c}\end{array}$ \\
\hline P1A3181 & Scaffold21:279,382:282,014 & Pleurotus ostreatus & DyP-type peroxidase & KDQ23617.1 & 0 & 978 & $98 \%$ & $\begin{array}{l}\text { Phosphatidylinositol- } \\
\text { specific phospholipase } \\
\text { C, X domain (PI-PLC-X) }\end{array}$ \\
\hline P1A3182 & Scaffold21:286,461:287,968 & Coprinopsis cinerea & $\begin{array}{l}\text { pheromone B alpha } \\
1 \text { receptor }^{d}\end{array}$ & KYQ37470.1 & $1 e^{-150}$ & 444 & $66 \%$ & STE3 domain \\
\hline P1A3183 & Scaffold21:290,001:290,769 & P. ostreatus & hypothetical protein & KDQ24181.1 & $1 e^{-57}$ & 195 & $57 \%$ & unknown \\
\hline P1A3184 & Scaffold21:295,700:299,143 & Rhizoctonia solani & $\begin{array}{l}\text { meiotically up- } \\
\text { regulated gene }\end{array}$ & CCO29943.1 & $2 e^{-72}$ & 261 & $70 \%$ & Myb_DNA-binding \\
\hline P1A3185 & Scaffold21:299,628:301,098 & P. ostreatus & hypothetical protein & KDQ23613.1 & 0 & 369 & $90 \%$ & Lipase_GDSL_2 \\
\hline P1A3186 & Scaffold21:306,804:307,565 & P. ostreatus & hypothetical protein & KDQ24181.1 & $1 e^{-49}$ & 173 & $52 \%$ & unknown \\
\hline P1A3187 & Scaffold21:310,133:310,684 & P. ostreatus & hypothetical protein & KDQ23624.1 & $6 e^{-91}$ & 275 & $82 \%$ & unknown \\
\hline P1A3188 & Scaffold21:312,158:313,474 & P. enyngii var. eryngii & $\begin{array}{l}\text { pheromone } \\
\text { receptor }\end{array}$ & AHL45286.1 & $2 e^{-179}$ & 512 & $94 \%$ & STE3 domain \\
\hline P1A3189 & Scaffold21:315,076:316,701 & P. populinus & $\begin{array}{l}\text { pheromone } \\
\text { receptor }\end{array}$ & AAS16508.1 & $7 e^{-116}$ & 345 & $98 \%$ & STE3 domain \\
\hline matpp21 & Scaffold21:318,257:318,454 & $\begin{array}{l}\text { P. eryngii var. } \\
\text { eryngii }\end{array}$ & $\begin{array}{l}\text { fungal mating-type } \\
\text { pheromone }\end{array}$ & AHL45289.1 & $2 e^{-04}$ & 43.9 & $80 \%$ & Pheromone \\
\hline P1A3190 & Scaffold21:320,014:321,378 & C. cinerea & $\begin{array}{l}\text { pheromone } \\
\text { receptor }\end{array}$ & XP_001834393.1 & $3 e^{-114}$ & 350 & $54 \%$ & STE3 domain \\
\hline P1A3191 & Scaffold21:321,830:323,841 & P. ostreatus & hypothetical protein & KDQ23243.1 & 0 & 810 & $84 \%$ & Methyltransf_2 \\
\hline matpp22 & Scaffold22:391,269:392,324 & P. ostreatus & $\begin{array}{l}\text { B mating-type } \\
\text { pheromone }\end{array}$ & KDQ23638.1 & $7 e^{-18}$ & 189 & $88 \%$ & Pheromone ${ }^{e}$ \\
\hline P1A3343 & Scaffold22:397,296:398,307 & P. ostreatus & $\begin{array}{l}\text { pheromone } \\
\text { receptor }\end{array}$ & KDQ23635.1 & $7 e^{-98}$ & 306 & $65 \%$ & STE3 domain \\
\hline
\end{tabular}

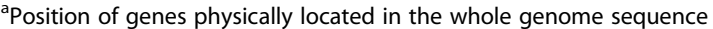

${ }^{b}$ Proteins of the highest identity with that in P. ostreatus, P. eryngii var. eryngii, C. cinerea, P. populinus, Rhizoctonia solani

${ }^{c}$ Conserved domains identified by Pfam 30.0 search

${ }^{\mathrm{d}}$ Pheromone and pheromone receptors highlighted in bold

'The conserved domain of matpp22 was not found by Pfam 30.0 search

The recombination rates (defined as the size ratio of the linkage map and the genome) of $P$. tuoliensis is comparable to that of $P$. ostreatus $(34 \mathrm{~kb} / \mathrm{cM})$ [10] but higher than that of $P$. eryngii $(26 \mathrm{~kb} / \mathrm{cM})$ [40]. The recombination rates varies along chromosomes, and the interval of high recombination rates may suggest the existence of recombination hotspots (Additional file 9). High recombination rate generates abundant genetic variations among individuals of the segregating population. The high level of co-segregating SNPs and the intervals of low recombination rates may suggest also the existence of the recombination cold spots. Suppressed recombination was reported frequently in basidiomycetes [41]. An extreme example is the button mushroom A. bisporus var. bisporus, where COs are restricted to chromosome ends [9].

The genome size of $P$. tuoliensis is $40.8 \mathrm{Mb}$, and that of the king oyster mushroom $P$. eryngii var. eryngii is 44.6 Mb (ATCC 90797) (http://genome.jgi.doe.gov). The two genomes presented a high level of synteny with hardly any inversion. The number of LG and map length

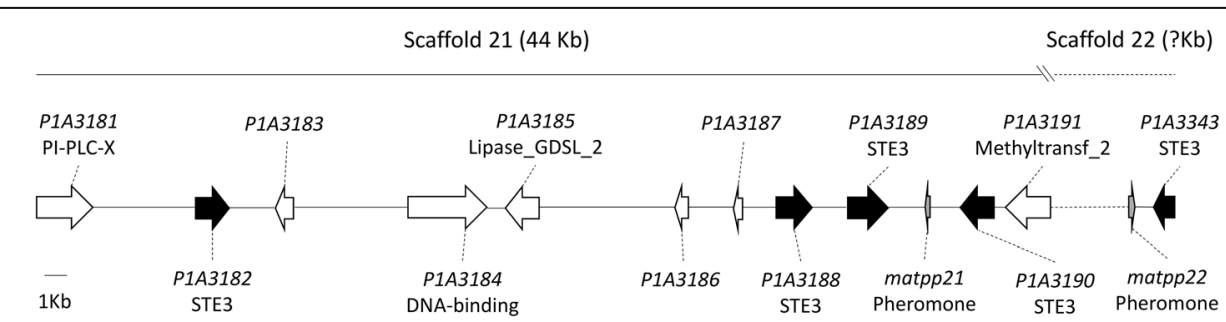

Fig. 5 A draft physical map of mating type B locus of $P$. tuoliensis. Black arrows indicate the five identified pheromone receptors, and the small grey arrows indicate the pheromone precursors identified on scaffold 21 and 22. The arrow direction indicates the transcription direction of individual genes 


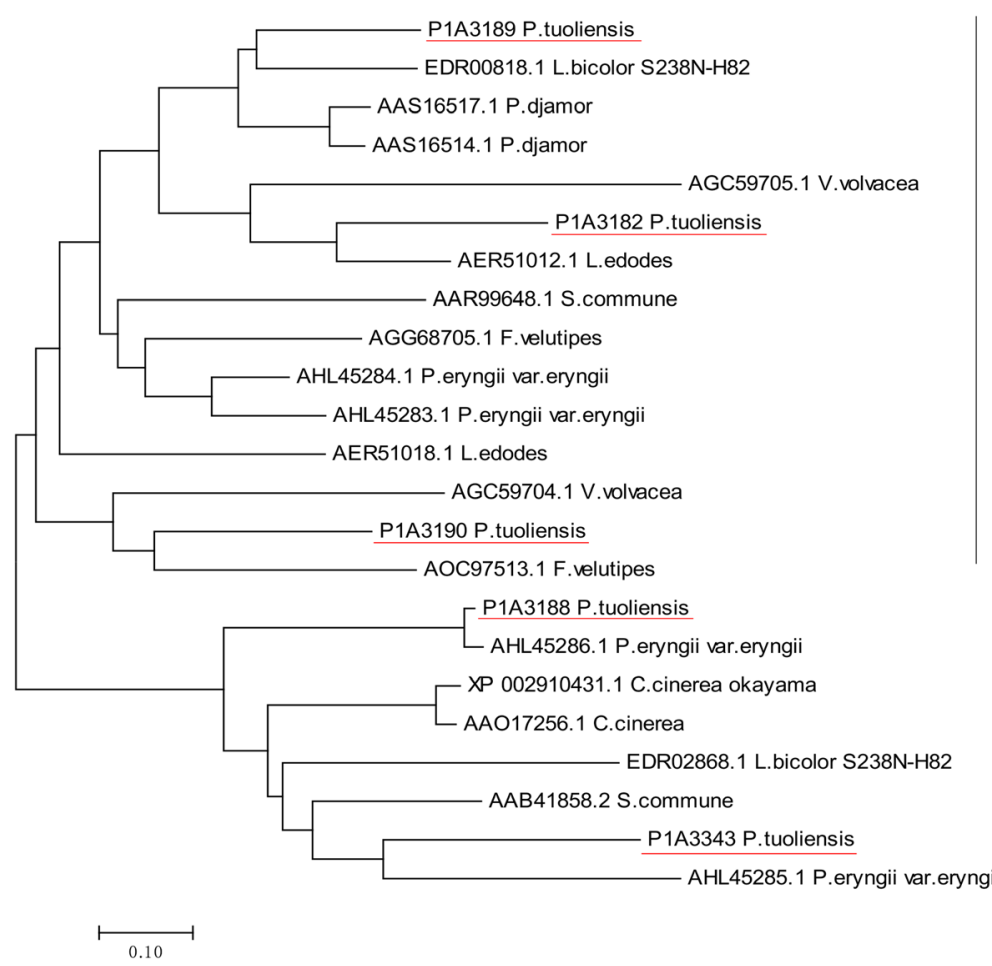

Clade A

Clade B

Fig. 6 Phylogenetic relationships of mushroom pheromone receptors. The five pheromone receptors identified in this study are underlined. The other sequences are presented with their GenBank accession numbers and the species names

of P. tuoliensis are comparable to that of P. eryngii var. eryngii [14]. The number of predicted gene models and the genome coverage of genes is slightly lower in $P$. tuoliensis (14,263 in P. tuoliensis and 15,960 in P. eryngii), which is consistent with the comparable genome size. The mapped markers were distributed homogenously over 78 anchored scaffolds and covered the majority $(83.1 \%)$ of the genome $(33.9 \mathrm{Mb})$. The marker order (cM) and physical position on scaffolds are not always coherent (Additional file 3). That is often seen in mapping programs for regions with very low or no recombination $[42,43]$. The chromosome assignment and the even spread of markers demonstrated that the linkage map presented here is generally saturated and it encompasses most of the Bailinggu genome. A total of 50.9\% SNP markers were discovered within the annotated coding regions, which was generally comparable to the ratio $(47.7 \%)$ that the total coding sequences occupying the entire genome. The SNP markers located in the coding regions may facilitate the candidate gene prediction and function analysis in further QTL studies for agronomical important traits; the ones located in the non-coding regions may play roles in regulating gene transcription and translation, which may also contribute to the expression of traits [44]. Totally, 97.4\% of the SNP markers (1151) were physically localized on scaffolds of the Bailinggu draft genome indicating a high similarity between genomes of the commercial line CCMSS00489 and the wild line CCMSS00485. Markers not anchored on scaffolds may indicate the sequence difference between the two parental genomes.

The order and the transcription direction of genes of matA within the entire locus was consistent in $P$. tuoliensis and P. eryngii var. eryngii. According to the genome sequence, the flanking gene mip was located distant $(28.5 \mathrm{~kb})$ from matA in $P$. tuoliensis, while mip was located next to matA in P. eryngii var. eryngii. However, the result of PCR amplification showed that the large sequence fragment between mip and matA was probably resulted from misassembly. Four pheromone receptors and four precursor genes were reported in P. eryngii var. eryngii [28]. In this study, a BLAST search for pheromone and pheromone receptors identified five pheromone receptors and two pheromone precursors within the matB region in $P$. tuoliensis. Pheromone precursors are usually as short as $100 \mathrm{AA}$ or less and variable in sequences, which make them difficult to be predict and detect only using search algorithms among the genome sequences [26]. Only the one on scaffold 21 showed a sequence similarity high enough to be identified via Pfam search. Nevertheless, the one on scaffold 22 showed a high identity to the pheromone reported in P. ostreatus PC15 [45]. A functional analysis of these 
candidates might be conducted with an expression system previously designed to analyze pheromone genes in Schizophyllum commune [46].

\section{Conclusions}

This study presented the first genome analysis of an important cultivated mushroom in China, $P$. tuoliensis. The de novo sequenced and annotated genome, assembled using a $2 \mathrm{~b}-\mathrm{RAD}$ generated linkage map, provides a base for marker-assisted breeding of this economic important mushroom species.

\section{Methods \\ Mapping population and DNA extraction}

The mapping population consists of 115 monokaryons of a dikaryotic strain H6. In order to isolate SSIs with a large range of germination and growth rate, we plated the spore suspension with a serial dilution steps. In order to have an unbiased selection of germinated spores SSIs were isolated from each dilution during one month. H6 is a hybrid strain developed in a previous breeding program. Parent H6PA is a monokaryotic single spore isolate (SSI) of a commercial cultivar CCMSSC00489, and parent $\mathrm{H} 6 \mathrm{~PB}$ is a monokaryotic SSI of a wild strain CCMSSC00485. The haploidy of monokaryon was determined under the microscope with the absence of clamp connections. Only dikaryons have the clamp connections, and SSI without are thus by definition monokaryons. Next to it, individuals of the segregating population were selected randomly among the determined monokaryons. The total genomic DNA was extracted from freeze-dried mycelia with the Wizard Magnetic 96 DNA Plant System (Promega) following the manufacture's protocol. The DNA concentration was adjusted to $20 \mathrm{ng} / \mu \mathrm{L}$. The two monokaryotic parental lines (489P1 and 489P2) of CCMSSC00489 were recovered through protoplasting. Strain 489P1 was used for the whole genome sequencing. All the dikaryotic strains (H6, CCMSSC00489, and CCMSSC00485) used in this study were obtained from CCMSSC, and all the monokaryotic strains generated in this study were deposited in CCMSSC.

\section{De novo genome sequencing}

A homokaryotic strain 489P1 was de novo sequenced on the platform of HighSeq 2500 by PE125 strategy. Two DNA libraries were constructed with a read length of $125 \mathrm{bp}$ : a paired-end library with an insert size of $500 \mathrm{bp}$ and a mate-pair library with an insert size of $5 \mathrm{~kb}$. Library construction and sequencing were performed at Beijing Novogene Bioinformatics Technology Co., Ltd. After quality control of both paired-end and mate-pair reads, Illumina PCR adapter reads and low quality reads were filtered. The filtered reads were assembled by
SOAPdenovo to generate scaffolds. All reads were used for gap closure. Components of the genome were predicted including protein-coding genes, non-coding RNA and repetitive sequence. Gene prediction was performed on the assembled genome using BRAKER1 (version 1.9) [47] by integrating the transcriptomic data of $P$. tuoliensis (accession number of NCBI: SRR2080100) [48]. The protein-coding genes were confirmed by using BLAST+ (version 2.2.31) against the NCBI non-redundant database (NR) with an E-value cutoff of $1 \mathrm{e}^{-5}$. Dispersed repeated sequences were predicted with the software of RepeatMasker through aligning the genome sequence with repeat databases (eg. Repbase); tandem repeats (TR) were searched via TRF (Tandem Repeats Finder). TRs were first modelled by percentage validation and the copy frequency of adjacent model InDels (Inserts and deletions), and were identified next with certain statistical criteria. Non-coding RNAs were blasted and annotated via Pfam software and database. Colinearity between the genomes of $P$. tuoliensis and $P$. eryngii var. eryngii (ATCC90797, JGI) was analyzed by using MUMmer version 3.1 [49] with different settings, i.e., mincluster $=2000$ for the whole genome comparison and mincluster $=1000$ for the scaffold.

\section{Genotyping by $2 \mathrm{~b}-\mathrm{RAD}$ approach}

2b-RAD libraries were prepared and analyzed at Oebiotech (Shanghai) for the two parents and 115 progeny by following the protocol developed by Wang et al. [18]. The libraries were constructed using adaptors with "NNN" overhangs to target the subset of Bsa XI fragments. All the libraries were pooled for single-end sequencing on the Hiseq2500 platform. Raw reads were first trimmed to remove low-quality ones during data processing. Reads without the Bsa XI restriction sites or containing long homopolymers ( $>10$ bp with quality of $<20)$ and successively identical bases (>10 bp) were removed. Reference sites were reconstructed using sequencing data of the two parents. The trimmed, high-quality reads of the parents and progeny were mapped to the representative reference sequences of the parents by SOAP2 [50].

\section{Linkage analysis and map construction}

SNP markers were used for linkage analysis. Expected Mendelian segregation (1:1) were tested for each locus by a $X^{2}$ test. Linkage mapping was performed using Joinmap 4.0 software with the model of HAP1. Makers showing more than $20 \%$ of missing data and/or skewed segregations $(P<0.05)$ were discarded. Linkage groups were determined by pair-wise analysis with a LOD score of 6.0 to assign markers to linkage groups. The regression mapping algorithm was selected for map 
construction. The Kosambi's mapping function was used to determine the map distances.

\section{Physical mapping over the genome sequence}

SNP markers obtained were localized physically on scaffolds of the genome. The core sequences of the marker locus were aligned to the genome by using BLAST+ (version 2.2.31) with an E-value cutoff of $1 \mathrm{e}^{-3}$ and a word size of 20 to order markers on scaffolds. Scaffolds were anchored on chromosomes by comparing marker positions on scaffolds and positions on the genetic map. Scaffolds were mapped only if they contain at least two SNPs. The graphical presentations of the genomic features and the physical map integrated with genetic linkage map were generated by using Circos 0.69 [51].

\section{Mapping of mating type locus}

The 115 monokaryotic individuals were first crossed with the two parental lines H6PA and H6PB. All mating tests were made on PDA plates. Cultures were grown at $25{ }^{\circ} \mathrm{C}$ for 10 days. Each paring was checked under the microscope for the presence or absence of clamp connections. The mating type of CCMSSC00489 was defined as $\mathrm{A} 1 \mathrm{~A} 2 \mathrm{~B} 1 \mathrm{~B} 2$ in a previous study, and that of 489P1 was A1B1. H6PA and H6PB was then identified as $\mathrm{A} 1 \mathrm{~B} 1$ and $\mathrm{A} 3 \mathrm{~B} 3$ by mating tests, respectively. Mating types of all the monokaryotic individuals were determined by the mating tests and confirmed by the genotypes of the flanking markers. Predicted gene sequences were analyzed for homology by using BlastX with a $P$ value threshold of $<10^{-10}$. Homologs of pheromone precursors were searched among the genome of $P$. tuoliensis via tBlastn of BioEdit program [52]. Genes and their conserved motifs were identified with Pfam 30.0 searches (http://pfam.xfam.org/). Previously reported pheromone receptors of mushroom species, i.e., $L$. edodes [26], P. djamor [27], P. eryngii var. eryngii [28], Flamulina velutipes [53], Coprinopsis cinerea [33, 54], Volvariella volvacea [55], Schizophyllum commne [56, 57], Laccaria bicolor [58] were used to do the phylogenetic analysis with that of $P$. tuoliensis. Sequences of the pheromone receptors were obtained from GenBank. Phylogenetic analysis of pheromone receptors was conducted by using BioEdit for multiple alignments and MEGA7.0.21 for estimating the phylogenetic relationships [59]. The phylogenetic tree was derived by the method of neighbor-joining and the bootstrap support of 1000 replicates.

\section{Additional files}

Additional file 1: Frequency distribution of the number of crossovers per individual. The number of crossovers per individual ranged from 3 to
17 with an average of 10 . The frequency distribution of crossovers in the progeny showed an almost normal distribution. (PDF 42 kb)

Additional file 2: Annotation of interspersed repeats of $P$. tuoliensis genome. (XLSX 289 kb)

Additional file 3: Marker information of the genetic linkage and physical map. The table summarizes the information of markers mapped genetically and physically, including the positions on genetic linkage map and scaffolds. (XLSX 63 kb)

Additional file 4: Markers mapped to LG1 of $P$. eryngii var. eryngii and their physical positions (Modified from Im et al., 2016). Primer sequences of markers were blasted to the whole genome sequence of ATCC90797 $(J G I)$. Physical positions of markers were indicated as the start and end positions of the primers. (XLSX $12 \mathrm{~kb}$ )

Additional file 5: Synteny comparison of the genomic regions of the $A$ mating-type locus and the flanking regions between $P$. tuoliensis and $P$. eryngii var. eryngii by using the assembled genome sequence in ChromoMapper [60]. Arrows indicate the location and transcription direction of individual genes. Lines connect homologous genes of the two species.

Abbreviations represent the function domain of genes, i.e., HYP for hypothetical protein; BFG for $\beta$ flanking protein; HD for homeodomain transcription factors; MIP for mitochondrial intermediate peptidase; RTL for rootletin-like protein. Details of genes within the compared genomic regions were available in Additional file 6. (TIFF $2257 \mathrm{~kb}$ )

Additional file 6: Genes of the A mating type locus and the flanking regions. The table shows the genes used for the synteny comparison of the A mating type locus and the flanking region in $P$. tuoliensis (this study, 489P1) and P. eryngii var. eryngii (JGl, ATCC 90797). (XLSX 10 kb)

Additional file 7: PCR for the fragment between genes of HD1 and mip. In order to confirm the distance between HD1 and mip, primers were designed using the CDNA sequences of HD1 and MIP. Primer sequences and their genome positions were as follows: Forward: 5' agcttacctcggaaccagt 3' (Scaffold6: 246,091-246,109); Reverse: 5' cgacagaattcgtgctgacc 3' (Scaffold6: 277,846-277,865). Each PCR $(20 \mu \mathrm{L})$ contained $10 \mathrm{ng}$ DNA template, $1 \times$ PCR buffer, $250 \mu \mathrm{M}$ each dNTP, 10 pmol primer, $0.5 \cup$ Taq DNA polymerase. Amplifications were performed as follows: after an initial denaturing step at $94{ }^{\circ} \mathrm{C}$ for $5 \mathrm{~min}$, the samples were processed through 35 cycles, each consisting of $30 \mathrm{~s}$ at $94{ }^{\circ} \mathrm{C}, 30 \mathrm{~s}$ at annealing temperature $55^{\circ} \mathrm{C}$ and $90 \mathrm{~s}$ at $72{ }^{\circ} \mathrm{C}$, and a final extension step at $72{ }^{\circ} \mathrm{C}$ during $5 \mathrm{~min}$. PCR products were separated on $1 \%$ agarose gels. The size of the PCR fragments indicate the misassembly of scaffold 6. (TIFF $438 \mathrm{~kb}$ )

Additional file 8: Sequence alignment of pheromone and pheromonelike peptides. The figure shows a multiple alignment of pheromone protein sequences of different mushroom species via ClastalW, i.e., A. bisporus, L. edodes, P. djamor, P. eryngii var. eryngii, P. ostreatus, and P. tuoliensis. The last four pheromone-like peptides were identified in $P$. tuoliensis of this study. Conservation of AA motifs is indicated by shading with different colors. (TIFF $196 \mathrm{~kb}$ )

Additional file 9: Recombination rates on a representative scaffold of each linkage group. Since several scaffolds were assigned to one LG (chromosome), we selected the longest scaffold (or a part of the scaffold for the ones divided into different LGS) as the representative. The physical positions of markers were plotted against the map positions, scatter plots were made for each linkage group. The red brackets indicate the physical positions of the high recombination rate suggesting the existence of recombination hotspots. The same scale was used for the Xaxis in order to make the map distance of different LG more comparable. (ZIP $1562 \mathrm{~kb})$

\section{Abbreviations}

2b-RAD: type IIB restriction-site associated DNA; CCMSSC: China Center for Mushroom Spawn Standards and Control; LG: Linkage group; LINEs: Long interspersed nuclear elements; LTR: Long terminal repeats; matA: mating type locus A; matB: mating type locus B; ncRNA: non-coding RNA; RC: Rolling circle; SINEs: Short interspersed nuclear elements; SNP: Single nucleotide polymorphism; SSI: Single spore isolate 


\section{Acknowledgements}

We are grateful for the transcriptomic data supported by Dr. Yongping Fu from Jilin Agricultural University. We thank Oebiotech, Shanghai and Novogene, Beijing for their technical support and advises on genotyping and sequencing data analyses.

\section{Funding}

This study was funded by the National Basic Research Program of China (2014CB138305), the National Nonprofit Institute Research Grant of Chinese Academy of Agricultural Sciences (CAAS, IARRP-647-46), and China Agriculture Research System (CARS20). Project 2014CB138305 funded the mapping and data analyses; project IARRP-647-46 (CAAS), funded the 2b-RAD sequencing and genotyping; project CARS20 funded the whole genome sequencing and analyses.

\section{Availability of data and materials}

All data generated or analyzed during this study are included in this published article and its Additional files. The phylogeny data of the pheromone receptors are available in the Treebase repository, http:// purl.org/phylo/treebase/phylows/study/TB2:S22027. The genome sequence of Pleurotus tuoliensis is available at GenBank database under the accession number MKZXX0000000.

\section{Authors' contributions}

WG carried out the genetic linkage mapping and mating type identification. $\mathrm{JQ}$ and WG conducted the physical mapping of the de novo sequenced genome and genome collinear analyses. WG, JQ, AS and $\mathrm{CH}$ wrote the manuscript and analyzed the results. All authors were involved in drafting and revising the manuscript. WG, JZ, AS and $\mathrm{CH}$ contributed to the design of the study. QC provided the parental lines and contributed to the population construction. $Y Z$ carried out the mating and identification of crossings. JZ and $Y Z$ contributed to the annotation and phylogeny analyses of genes located in the mating type loci. JZ and CH coordinated the projects. All authors read and approved the final manuscript.

\section{Ethics approval and consent to participate}

Not applicable

\section{Consent for publication}

Not applicable

\section{Competing interests}

The authors declare that they have no competing interests.

\section{Publisher's Note}

Springer Nature remains neutral with regard to jurisdictional claims in published maps and institutional affiliations.

\section{Author details}

'Institute of Agricultural Resources and Regional Planning, Chinese Academy of Agricultural Sciences, Beijing, China. ${ }^{2}$ Key Laboratory of Microbial Resources, Ministry of Agriculture, Beijing, China. ${ }^{3}$ Plant Breeding, Wageningen University \& Research Centre, 6708, PB, Wageningen, The Netherlands.

Received: 10 July 2017 Accepted: 27 December 2017

Published online: 05 January 2018

\section{References}

1. Zhang JX, Huang CY, Ng TB, Wang HX. Genetic polymorphism of ferula mushroom growing on Ferula sinkiangensis. Appl Microbiol Biotechnol. 2006;71(3):304-9.

2. Mu C, Cao Y, Ma JA. New variety of Pleurotus ferula and its culture characters. Acta Mycol Sin. 1987;6:153-6.

3. Zhao M, Zhang J, Chen Q, Wu X, Gao W, Deng W, Huang C. The famous cultivated mushroom Bailinggu is a separate species of the Pleurotus eryngii species complex. Sci Rep. 2016:6:33066

4. Kawai G, Babasaki K, Neda H. Taxonomic position of a Chinese Pleurotus "Bai-Ling-Gu": it belongs to Pleurotus eryngii (DC.: Fr.) Quel. And evolved independently in China. Mycoscience. 2008;49(1):75-87.
5. Zervakis Gl, Ntougias S, Gargano ML, Besi Ml, Polemis E, Typas MA, Venturella GA. Reappraisal of the Pleurotus eryngii complex - new species and taxonomic combinations based on the application of a polyphasic approach, and an identification key to Pleurotus taxa associated with Apiaceae plants. Fungal Biol. 2014;118(9-10):814-34.

6. Dong H, Lu Z. Studies on isolation, purification and antitumor anctivity of polysaccharides of Pleurotus ferulae. Microbiology China. 2003;30(2):16-9.

7. Kerrigan RW, Royer JC, Baller LM, Kohli Y, Horgen PA, Anderson JB. Meiotic behavior and linkage relationships in the secondarily homothallic fungus Agaricus bisporus. Genetics. 1993;133(2):225-36.

8. Foulongne-Oriol M, Spataro C, Cathalot V, Monllor S, Savoie JM. An expanded genetic linkage map of an intervarietal Agaricus bisporus var. bisporus $\times$ A. bisporus var. burnettii hybrid based on AFLP, SSR and CAPS markers sheds light on the recombination behaviour of the species. Fungal Genet Biol. 2010:47(3):226-36.

9. Sonnenberg AS, Gao W, Lavrijssen B, Hendrickx P, Sedaghat-Tellgerd N, Foulongne-Oriol M, Kong WS, Schiilen EG, Baars JJ, Visser RG. A detailed analysis of the recombination landscape of the button mushroom Agaricus bisporus var. bisporus. Fungal Genet Biol. 2016;93:35-45.

10. Larraya LM, Perez G, Ritter E, Pisabarro AG, Ramirez L. Genetic linkage map of the edible basidiomycete Pleurotus ostreatus. Appl Environ Microbiol. 2000;66(12):5290-300

11. Larraya LM, Alfonso M, Pisabarro AG, Ramirez L. Mapping of genomic regions (quantitative trait loci) controlling production and quality in industrial cultures of the edible basidiomycete Pleurotus ostreatus. Appl Environ Microbiol. 2003;69(6):3617-25.

12. Gong WB, Liu W, YY L, Bian YB, Zhou Y, Kwan HS, Cheung MK, Xiao Y. Constructing a new integrated genetic linkage map and mapping quantitative trait loci for vegetative mycelium growth rate in Lentinula edodes. Fungal Biology. 2014;118(3):295-308.

13. Kwan HS, Xu HL. Construction Of a genetic linkage map of shiitake mushroom Lentinula edodes strain L-54.J Biochem Mol Biol. 2002;35(5):465-71.

14. Im CH, Park YH, Hammel KE, Park B, Kwon SW, Ryu H, Ryu JS. Construction of a genetic linkage map and analysis of quantitative trait loci associated with the agronomically important traits of Pleurotus eryngii. Fungal Genet Biol. 2016;

15. Okuda Y, Ueda J, Obatake Y, Murakami S, Fukumasa Y, Matsumoto T. Construction of a genetic linkage map based on amplified fragment length polymorphism markers and development of sequence-tagged site markers for marker-assisted selection of the sporeless trait in the oyster mushroom (Pleurotus eryngii). Appl Environ Microbiol. 2012;78(5):1496-504

16. Foulongne-Oriol M, Rocha de Brito M, Cabannes D, Clement A, Spataro C, Moinard M, Dias ES, Callac P, Savoie JM. The genetic linkage map of the medicinal mushroom Agaricus subrufescens reveals highly conserved Macrosynteny with the congeneric species Agaricus bisporus. G3 (Bethesda). 2016;6(5):1217-26

17. Davey JW, Blaxter ML. RADSeq: next-generation population genetics. Brief Funct Genomics. 2010;9(5-6):416-23.

18. Wang S, Meyer E, McKay JK, Matz MV. 2b-RAD: a simple and flexible method for genome-wide genotyping. Nat Methods. 2012;9(8):808-10.

19. Guo Y, Yuan H, Fang D, Song L, Liu Y, Liu Y, Wu L, Yu J, Li Z, Xu X, et al. An improved $2 \mathrm{~b}-\mathrm{RAD}$ approach (I2b-RAD) offering genotyping tested by a rice (Oryza sativa L.) F2 population. BMC Genomics. 2014;15:956.

20. Jiao WQ, XT F, Dou JZ, Li HD, HL S, Mao JX, Yu Q, Zhang LL, XL H, Huang $X T$, et al. High-resolution linkage and quantitative trait locus mapping aided by genome survey sequencing: building up an integrative genomic framework for a bivalve Mollusc. DNA Res. 2014;21(1):85-101.

21. Seetharam AS, Stuart GW. Whole genome phylogeny for 21 Drosophila species using predicted 2b-RAD fragments. PeerJ. 2013;1:e226.

22. Kothe E. Mating-type genes for basidiomycete strain improvement in mushroom farming. Appl Microbiol Biotechnol. 2001;56(5-6):602-12.

23. Raudaskoski M, Kothe E. Basidiomycete mating type genes and pheromone signaling. Eukaryot Cell. 2010;9(6):847-59.

24. CH A, Wong MC, Bao D, Zhang M, Song C, Song W, Law PT, Kues U, Kwan HS. The genetic structure of the a mating-type locus of Lentinula edodes. Gene. 2014;535(2):184-90.

25. Xu J, Kerrigan RW, Horgen PA, Anderson JB. Localization of the mating type gene in Agaricus bisporus. Appl Environ Microbiol. 1993;59(9):3044-9.

26. Wu L, van Peer A, Song W, Wang H, Chen M, Tan Q, Song C, Zhang M, Bao D. Cloning of the Lentinula edodes B mating-type locus and identification of the genetic structure controlling B mating. Gene. 2013;531(2):270-8. 
27. James TY, Liou SR, Vilgalys R. The genetic structure and diversity of the a and B mating-type genes from the tropical oyster mushroom, Pleurotus djamor. Fungal Genet Biol. 2004;41(8):813-25.

28. Kim KH, Kang YM, Im CH, Ali A, Kim SY, Je HJ, Kim MK, Rho HS, Lee HS, Kong WS, et al. Identification and functional analysis of pheromone and receptor genes in the B3 mating locus of Pleurotus eryngii. PLoS One. 2014 9(8):e104693.

29. Ryu JS, Kim MK, Ro HS, Kang YM, Kwon JH, Kong WS, Lee HS. Identification of mating type loci and development of SCAR marker genetically linked to the B3 locus in Pleurotus eryngii. J Microbiol Biotechnol. 2012;22(9):1177-84.

30. Chen B, van Peer AF, Yan J, Li X, Xie B, Miao J, Huang Q, Zhang L, Wang W, Fu J, et al. Fruiting body formation in Volvariella volvacea can occur independently of its MAT-A-controlled bipolar mating system, enabling homothallic and heterothallic life cycles. G3 (Bethesda). 2016;6(7):2135-46.

31. Kües U, James TY, Heitman J. Mating Type in Basidiomycetes: Unipolar, Bipolar, and Tetrapolar Patterns of Sexuality. In: Pöggeler S, Berlin WJ, Heidelberg, editors. Evolution of Fungi and Fungal-Like Organisms. Springer: Berlin Heidelberg; 2011. p. 97-160.

32. Casselton LA, Challen MP. The Mating Type Genes of the Basidiomycetes. In: Growth, Differentiation and Sexuality. Edited by Kües U, Fischer R. Berlin, Heidelberg: Springer Berlin Heidelberg; 2006: 357-74

33. Riquelme $M$, Challen MP, Casselton LA, Brown AJ. The origin of multiple $B$ mating specificities in Coprinus cinereus. Genetics. 2005;170(3):1105-19.

34. Specht CA. Isolation of the B alpha and B beta mating-type loci of Schizophyllum commune. Curr Genet. 1995;28(4):374-9.

35. Page DE, Glen M, Ratkowsky DA, Beadle CL, Rimbawanto A, Mohammed CL. Ganoderma basidiospore germination responses as affected by spore density, temperature and nutrient media. Tropical Plant Pathology. 2017;42(5):328-38.

36. Castanera R, Borgognone A, Pisabarro AG, Ramirez L. Biology, dynamics, and applications of transposable elements in basidiomycete fungi. Appl Microbiol Biotechnol. 2017;101(4):1337-50.

37. Castanera R, Lopez-Varas L, Borgognone A, LaButti K, Lapidus A, Schmutz J, Grimwood J, Perez G, Pisabarro AG, Grigoriev IV, et al. Transposable elements versus the fungal genome: impact on whole-genome architecture and transcriptional profiles. PLoS Genet. 2016;12(6):e1006108.

38. Hake AA, Shirasawa K, Yadawad A, Sukruth M, Patil M, Nayak SN, Lingaraju S, Patil PV, Nadaf HL, Gowda MVC, et al. Mapping of important taxonomic and productivity traits using genic and non-genic transposable element markers in peanut (Arachis hypogaea L.). PLoS One. 2017;12(10):e0186113.

39. Stuart T, Eichten SR, Cahn J, Karpievitch YV, Borevitz JO, Lister R. Population scale mapping of transposable element diversity reveals links to gene regulation and epigenomic variation. elife. 2016;5

40. Im CH, Park YH, Hammel KE, Park B, Kwon SW, Ryu H, Ryu JS. Construction of a genetic linkage map and analysis of quantitative trait loci associated with the agronomically important traits of Pleurotus eryngii. Fungal Genet Biol. 2016;92:50-64.

41. Idnurm A, Hood ME, Johannesson H, Giraud T. Contrasted patterns in mating-type chromosomes in fungi: hotspots versus coldspots of recombination. Fungal Biol Rev. 2015;29(3-4):220-9.

42. Soto JC, Ortiz JF, Perlaza-Jimenez L, Vasquez AX, Lopez-Lavalle LA, Mathew B, Leon J, Bernal AJ, Ballvora A, Lopez CEA. Genetic map of cassava (Manihot esculenta Crantz) with integrated physical mapping of immunityrelated genes. BMC Genomics. 2015;16:190.

43. Gao W, Weijn A, Baars JJP, Mes JJ, Visser RGF, Sonnenberg ASM. Quantitative trait locus mapping for bruising sensitivity and cap color of Agaricus bisporus (button mushrooms). Fungal Genet Biol. 2015;77(0):69-81.

44. Salvi S, Sponza G, Morgante M, Tomes D, Niu X, Fengler KA, Meeley R, Ananiev EV, Svitashev S, Bruggemann E, et al. Conserved noncoding genomic sequences associated with a flowering-time quantitative trait locus in maize. Proc Natl Acad Sci U S A. 2007;104(27):11376-81.

45. Riley R, Salamov AA, Brown DW, Nagy LG, Floudas D, Held BW, Levasseur A, Lombard V, Morin E, Otillar R, et al. Extensive sampling of basidiomycete genomes demonstrates inadequacy of the white-rot/brown-rot paradigm for wood decay fungi. Proc Natl Acad Sci U S A. 2014;111(27):9923-8.

46. Kothe E, Gola S, Wendland J. Evolution of multispecific mating-type alleles for pheromone perception in the homobasidiomycete fungi. Curr Genet. 2003;42(5):268-75.

47. Hoff KJ, Lange S, Lomsadze A, Borodovsky M, Stanke M. BRAKER1: Unsupervised RNA-Seq-Based Genome Annotation with GeneMark-ET and AUGUSTUS. Bioinformatics. 2016:32(5):767-9.
48. YP F, Liang Y, Dai YT, Yang CT, Duan MZ, Zhang Z, SN H, Zhang ZW, Li Y. De novo sequencing and transcriptome analysis of Pleurotus eryngii subsp. tuoliensis (Bailinggu) mycelia in response to cold stimulation. Molecules. 2016;21(5)

49. Kurtz S, Phillippy A, Delcher AL, Smoot M, Shumway M, Antonescu C, Salzberg SL. Versatile and open software for comparing large genomes. Genome Biol. 2004:5(2):R12.

50. Li R, Yu C, Li Y, Lam TW, Yiu SM, Kristiansen K, Wang J. SOAP2: an improved ultrafast tool for short read alignment. Bioinformatics. 2009;25(15):1966-7.

51. Krzywinski M, Schein J, Birol I, Connors J, Gascoyne R, Horsman D, Jones SJ, Marra MA. Circos: an information aesthetic for comparative genomics. Genome Res. 2009;19(9):1639-45.

52. Altschul SF, Madden TL, Schaffer AA, Zhang J, Zhang Z, Miller W, Lipman DJ. Gapped BLAST and PSI-BLAST: a new generation of protein database search programs. Nucleic Acids Res. 1997;25(17):3389-402.

53. Wang W, Lian L, Xu P, Chou T, Mukhtar I, Osakina A, Wagas M, Chen B, Liu $X$, Liu F, et al. Advances in understanding mating type Gene Organization in the mushroom forming fungus Flammulina velutipes. G3 (Bethesda). 2016;

54. Stajich JE, Wilke SK, Ahren D, CH A, Birren BW, Borodovsky M, Burns C, Canback B, Casselton LA, Cheng CK, et al. Insights into evolution of multicellular fungi from the assembled chromosomes of the mushroom Coprinopsis cinerea (Coprinus cinereus). Proc Natl Acad Sci U S A. 2010; 107(26):11889-94.

55. Chen B, Gui F, Xie B, Deng Y, Sun X, Lin M, Tao Y, Li S. Composition and expression of genes encoding carbohydrate-active enzymes in the strawdegrading mushroom Volvariella volvacea. PLoS One. 2013;8(3):e58780.

56. Vaillancourt LJ, Raudaskoski M, Specht CA, Raper CA. Multiple genes encoding pheromones and a pheromone receptor define the B beta 1 mating-type specificity in Schizophyllum commune. Genetics. 1997;146(2): 541-51.

57. Fowler TJ, Mitton MF, Vaillancourt LJ, Raper CA. Changes in mate recognition through alterations of pheromones and receptors in the multisexual mushroom fungus Schizophyllum commune. Genetics. 2001; 158(4):1491-503.

58. Martin F, Aerts A, Ahren D, Brun A, Danchin EG, Duchaussoy F, Gibon J, Kohler A, Lindquist E, Pereda $\mathrm{V}$, et al. The genome of Laccaria bicolor provides insights into mycorrhizal symbiosis. Nature. 2008;452(7183):88-92.

59. Kumar S, Stecher G, Tamura K. MEGA7: molecular evolutionary genetics analysis version 7.0 for bigger datasets. Mol Biol Evol. 2016;33(7):1870-4.

60. Niculita-Hirzel H, Labbe J, Kohler A, le Tacon F, Martin F, Sanders IR, Kues U. Gene organization of the mating type regions in the ectomycorrhizal fungus Laccaria bicolor reveals distinct evolution between the two mating type loci. New Phytol. 2008;180(2):329-42.

\section{Submit your next manuscript to BioMed Central and we will help you at every step:}

- We accept pre-submission inquiries

- Our selector tool helps you to find the most relevant journal

- We provide round the clock customer support

- Convenient online submission

- Thorough peer review

- Inclusion in PubMed and all major indexing services

- Maximum visibility for your research

Submit your manuscript at www.biomedcentral.com/submit
Biomed Central 